\title{
Article \\ Comparison of Interview to Questionnaire for Assessment of Eating Disorders after Bariatric Surgery
}

\author{
Inbal Globus ${ }^{1,2}{ }^{\text {, Harry R. Kissileff }}{ }^{3,4}$, Jeon D. Hamm ${ }^{3,4,5} \mathbb{D}^{\mathbb{D}}$, Musya Herzog ${ }^{6} \mathbb{D}$, James E. Mitchell ${ }^{7}$ \\ and Yael Latzer $8,9, *$
}

Citation: Globus, I.; Kissileff, H.R.; Hamm, J.D.; Herzog, M.; Mitchell,

J.E.; Latzer, Y. Comparison of Interview to Questionnaire for Assessment of Eating Disorders after Bariatric Surgery. J. Clin. Med. 2021, 10, 1174. https://doi.org/10.3390/ jcm10061174

Academic Editor: Giacomo Mancini

Received: 14 January 2021

Accepted: 25 February 2021

Published: 11 March 2021

Publisher's Note: MDPI stays neutral with regard to jurisdictional claims in published maps and institutional affiliations.

Copyright: (c) 2021 by the authors. Licensee MDPI, Basel, Switzerland. This article is an open access article distributed under the terms and conditions of the Creative Commons Attribution (CC BY) license (https:// creativecommons.org/licenses/by/ $4.0 /)$.
1 School of Public Health, University of Haifa, 199 Aba Khoushy Ave., Mount Carmel, Haifa 3498838, Israel; inbal.balog@gmail.com

2 Maccabi Healthcare Services, Hamered 27, Tel-Aviv 6812509, Israel

3 Mount Sinai Morningside Hospital, 1111 Amsterdam Avenue, New York, NY 10025, USA;

Harry.Kissileff2@mountsinai.org (H.R.K.); jeonhamm@gmail.com (J.D.H.)

4 Diabetes, Obesity, and Metabolism Institute, Icahn School of Medicine at Mount Sinai, 1 Gustave L. Levy Pl, New York, NY 10029, USA

5 Institute of Human Nutrition, Vagelos College of Physicians \& Surgeons, Columbia University, 630 W 168th Street \#1512, New York, NY 10032, USA

6 Department of Counseling \& Clinical Psychology, Teachers College, Columbia University, 525 W 120th Street, New York, NY 10027, USA; musyaherzog@gmail.com

7 University of North Dakota School of Medicine, 1244 Wildwood Way, Chaska, MN 55318, USA; Mitchelljames7033@gmail.com

8 Faculty of Social Welfare and Health Sciences, University of Haifa, 199 Aba Khoushy Avenue, Mount Carmel, Haifa 3498838, Israel

9 Eating Disorders Institution, Rambam Health Care Campus, HaAliya HaShniya St. 8, Haifa 3109601, Israel

* Correspondence: latzery@gmail.com; Tel.: +972-54-4736673 or +1-917-935-1824

\begin{abstract}
The Eating Disorder Examination Interview Bariatric Surgery Version (EDE-BSV) assesses eating pathology after bariatric surgery but requires significant training and time to administer. Consequently, we developed a questionnaire format called the Eating Disorders After Bariatric Surgery Questionnaire (EDABS-Q). This study evaluates the consistency of responsiveness between the two formats. After surgery, 30 patients completed the EDE-BSV and EDABS-Q in a restricted randomized design. Patient reported behavior for each item which was converted to a score following the Eating Disorder Examination-Questionnaire (EDE-Q) scoring scheme. Responses fell into three distributions: (1) dichotomous, (2) ordinal, or (3) unimodal. Distributions of items were not different between the two formats and order did not influence response. Tests of agreement (normal approximation of the binomial test) and association ( $\chi^{2}$ analyses on binary data and spearman rank order correlations on ordinal items) were performed. Percent concordance was high across items (63-100\%). Agreement was significant in 31 of 41 items (Bonferroni-P < 0.001). Association was significant in 10 of 21 in $\chi^{2}$-appropriate items (Bonferroni-P $<0.002$ ), and the ordinal items had highly significant correlations between formats (Bonferroni-P < 0.0125). The EDABS-Q is an adequate substitute for the EDE-BSV and may be useful for research and clinical evaluation of eating pathology after bariatric surgery.
\end{abstract}

Keywords: bariatric surgery; eating disorders; eating pathology; questionnaire; binge eating disorders

\section{Introduction}

\subsection{Background}

Bariatric surgery is effective in limiting the ability of patients to continue a preoperative pattern of eating large quantities in a short period of time, i.e., to engage in binge eating episodes. However, many patients regain weight post-operation through other manifestations of maladaptive eating, some of which may be disordered [1]. Instruments to assess eating pathology (EP) in this population are limited [2] and fail to discriminate between EP and behaviors to relieve discomfort, such as involuntary vomiting, food intake 
restriction, increased meal frequency, and excessive chewing before swallowing [3-5]. A semi-structured interview to assess post-bariatric EP exists in the modified version of the Eating Disorder Examination (EDE) interview [6], the Eating Disorder ExaminationBariatric Surgery Version (EDE-BSV) [7]. Note: The EDE interview is a psychometrically validated instrument but the EDE-BSV is not. To the best of our knowledge, there is no self-report version of the EDE-BSV interview. An experienced interviewer and a significant amount of time is required to conduct the interview. Consequently, it is desirable to develop a self-report instrument based on this interview that is valid for use in a post-bariatric surgery population.

\subsection{Objectives}

This study describes the development of a self-report questionnaire (from the components of the Eating Disorder Examination-Questionnaire (EDE-Q) [8] and EDE-BSV interview) [7] that assesses eating disorders after bariatric surgery (EDABS-Q) that can potentially be used to assess EP in this population without the need of an interview. The interview was developed by experts in the field of eating disorder and bariatric surgery. They were well familiar with the EDE-Q questionnaire, which is a validated, well-known questionnaire used globally by researchers and clinicians concerned with disordered eating [7]. They published in detail the way they developed the questionnaire and how it was administered in a clinical setting. We used the wording described in their paper, but simply read the same words that were used in the questionnaire we developed from it. We hypothesized that responses from the interview and questionnaire will accord, regardless of the order in which they are administered.

\section{Materials and Methods}

\subsection{Study Participants}

Participant data were collected between August 2018 and June 2019 at several medical centers in Israel. Thirty individuals with a body mass index (BMI) $\geq 35 \mathrm{~kg} / \mathrm{m}^{2}$, scheduled to undergo one anastomoses gastric bypass surgery $(n=8)$ or sleeve gastrectomy $(n=22)$, were recruited before their scheduled surgery. Patients were wecruited upon arrival to the bariatric surgery committee Screening eligibility criteria were: (1) age: 18-65 years at the start of the study; (2) Jewish individuals from diverse cultural groups, and both sexes; (3) candidates without diagnosis of psychosis taking any antipsychotic medications, or acutely suicidal. We removed candidates with antipsychotic medications as according to the literature usually they do not get an approval for bariatric surgery.

\subsection{Description of Interview and Questionnaire}

The EDE-BSV consisted of the items that comprise the four symptom categories (or "subscales") in the EDE-Q [8]: eating concern, weight concern, shape concern, and restraint, however, was adapted in a few ways. Firstly, items that comprised the original restraint category, which is related to pathological behavior, were also extended to a new and revised restraint category, to avoid physical discomfort. Secondly, items pertaining to compensatory behaviors (such as vomiting, spitting and chewing, rumination, and use of laxatives and diuretics), which we have labelled "purging", were also included as a category. Furthermore, these items were classified into purging to avoid weight gain and purging to avoid physical discomfort. These items and categories were added because the motivation to avoid or mitigate physical discomfort after bariatric surgery could elucidate the endorsement of restriction and compensatory behaviors (Conceição et al., 2013). A self-report version of the EDE-BSV, called the EDABS-Q, was developed from the adapted EDE-BSV.

The text for all items included in the EDE-BSV and the EDABS-Q (scored and unscored) are in Appendix A (Table A1). Frequencies of behaviors (reported in days, 0-28) were converted into a 7-point ordinal scale according to the following scheme based on EDE$\mathrm{Q}$ [8], which we will refer to as "scaled scores": 0 days were scored as " 0 "; $1-5$ days were 
scored as " 1 "; 6-12 days were scored as " 2 "; $13-15$ days were scored as " 3 "; $16-22$ days were scored as " 4 "; $23-27$ days were scored as " 5 "; everyday was scored as " 6 ".

\subsection{Study Protocol}

The interview and questionnaire were administered in the Hebrew language, at least 1 year after surgery, in a restricted randomized design. Half of the patients received the EDE-BSV interview format first, and the other half, the EDABS-Q questionnaire format first. The EDABS-Q was administered through Qualtrics, and the interview responses were entered into the same Qualtrics program for comparison with the questionnaire. The wording of both the interview and questionnaire was identical. The only difference is that the interviewer read the questions and recorded the answers. The study was carried out in accordance with the latest version of the Declaration of Helsinki. Informed consent was obtained, and the protocol was approved by the Institutional Review Board at Assuta Medical Center, Israel.

\subsection{Data Analyses}

All data analyses were performed in SAS9.4 software (SAS Institute, Inc., Cary, NC, USA). Plots of frequency distributions for responses to each item were examined for uniformity across items. Due to the non-normality of the distribution of item responses, non-parametric analyses were used.

\subsubsection{Examination of the Distributions of All Items in the Interview and Questionnaire}

Univariate analyses were executed on all items in both formats (EDE-BSV and EDABS-Q). We expected there would be two distinct patterns of response: (1) binary (i.e., only extreme responses, such that predominant response was 0,1 or 5,6 ) or (2) ordinal, even distribution of responses across the 7-point scale.

In order to determine whether binary or ordinal analysis was appropriate for comparison of formats, we created a plot of the number of participants, out of 30 , whose scaled scores (0-6) for each item were in the middle of the range (a score of 2,3, or 4 out of the 7-point scheme, 0-6). A distribution suitable for ordinal analysis, as opposed to binary, would include roughly the same number of participants across all seven score types (0-6), and because we recruited 30 participants, we considered $4-5$ to be the expected count of participants for each of the seven scores $\left(\frac{30 \text { participants }}{7 \text { score types }}=4.5\right.$ participants $)$. Consequently, we would expect, assuming some variability, that the mean number of items in the range of $2-4$, would be the mathematical product of the number of participants in each score type (i.e., 4.5$) \times 3(2,3$, and 4 are three out of seven possible scores). Due to possible variability, the product could range from $9(3 \times 3)$ to $15(5 \times 3)$. Items with fewer than nine participants in the intermediate range were classified as dichotomous, while items that had nine or more participants in the intermediate range were considered suitable for ordinal analysis.

\subsubsection{Analysis Overview}

Two kinds of tests were conducted. "Agreement" (i.e., the proportion of the same responses to an item on the two formats) was assessed by the binomial test. "Association" (i.e., proportion of the same or different response or response pattern in one format compared to the other format) was assessed by means of chi-squared analyses (appropriate for dichotomous or binary data) and Spearman rank-order correlations (appropriate for the ordinal data). Final conclusions from significance tests were determined after the $p$-values were corrected for multiple comparisons by Bonferroni test (uncorrected $p$-value divided by k number of items). Both uncorrected and corrected results are presented. Given the relatively small sample size, conclusions should be considered tentative, although corrected $p$-values are likely to be reproducible. 


\subsubsection{Binomial Tests}

Significance of agreement of responses on the two formats was measured by means of the normal approximation of binomial test on the probability that response classes (presence or absence of a feature) on each format were identical. If significantly more individuals responded the same on both formats, than expected by chance (for a sample of 30 , more than 20 , i.e., $67.8 \%$, or $76 \%$ with Bonferroni correction), then the two formats agree for that item. The critical value (x) was computed from the sampling distribution of number of agreements on the formats, which is approximately normally distributed (z), by means of the formula $x=z \times \sqrt{N p q}$, where $N=30$ and $p$ and $q$ are the probabilities of agreement and non-agreement (Siegel, 1956). Additionally, a normal approximation of the binomial test was conducted on discordant pairs (i.e., positive response on one format but zero on the other) to determine whether the proportion of responses was greater on the questionnaire than interview and conversely.

\subsubsection{Chi-Square Analysis}

Frequencies of scaled scores (0-6) were grouped into four classes of pairs of scores for the same item in both formats (See Table 1). Pairs were assigned to individuals by the following rules: If scores of an item were zero (i.e., the behavior rated never occurred) for both formats, the individual's pair was assigned (" 0,0 "). If scores for both formats were 1 or greater (i.e., positive), the individual's pair was assigned ("1,1"). If scores for questionnaire were zero but scores for interview were 1 or greater, then the individual's pair was assigned (" 0,1 "). If scores for interview were positive, but scores for questionnaire were zero, the individual's pair was assigned (" 1,0 "). Concordant pairs are those in which the responses are the same (" 0,0 " or " 1,1 ") for the questionnaire and the interview, whereas discordant pairs are those for which the responses are different (" 0,1 " or " 1,0 ") between the versions. Thus a $2 \times 2$ matrix was constructed and chi-squared tests were conducted on the frequencies of these four pairs for each item in order to test whether frequencies of zero and positive responses were the same or different between the two formats. If the instruments are in agreement, the number of concordant pairs should be greater than the number of discordant pairs. The test of these differences is made by $\chi^{2}$ on the frequencies of the four possibilities, with the null hypothesis that frequencies in all cells would be the same. The $\chi^{2}$ test is the non-parametric equivalent of correlation, and the coefficient of contingency, $\mathrm{C}$ $\left(\sqrt{\frac{x^{2}}{N}}+x^{2}\right)$ is analogous to a regression coefficient. A significant $p$-value for chi-square is equivalent to a significant coefficient of contingency and should be interpreted that the two formats agree. The strength of association is given by the coefficient of contingency, which ranges from 0 to 1 . The chi-square test is not valid for expected values with frequencies of less than 1 in any of the four cells (Siegel, 1956). During computation of chi-square, the programming was set to report invalid tests, and these are noted in the results (Table 2). The Cohen's kappa ( $\kappa$ ) coefficient was also calculated as another measure of association of responses among all four categories, ranging from completely negatively correlated $(\kappa=-1.00)$ through completely random $(\kappa=0.00)$ to completely correlated $(\kappa=1.00)$. 
Table 1. Frequency of ordinal responses to the interview and questionnaire ${ }^{\text {a }}$.

\begin{tabular}{|c|c|c|c|c|c|c|c|c|c|c|c|c|c|c|c|}
\hline \multirow[b]{2}{*}{ Category } & \multirow[b]{2}{*}{ Item } & \multicolumn{7}{|c|}{ Interview } & \multicolumn{7}{|c|}{ Questionnaire } \\
\hline & & $\mathbf{0}$ & 1 & 2 & 3 & 4 & 5 & 6 & 0 & 1 & 2 & 3 & 4 & 5 & 6 \\
\hline Shape concern & 13. Days desiring flat stomach & 13 & 6 & 0 & 2 & 1 & 0 & 8 & 16 & 3 & 0 & 0 & 1 & 1 & 9 \\
\hline Shape concern & 15. Difficulty concentrating due to shape or weight concern & 24 & 3 & 0 & 0 & 0 & 0 & 3 & 24 & 1 & 2 & 1 & 1 & 0 & 1 \\
\hline Shape concern & 17. Fear of weight gain & 4 & 7 & 4 & 2 & 2 & 0 & 11 & 4 & 5 & 4 & 0 & 2 & 1 & 14 \\
\hline Shape concern & 18. Feeling fat & 18 & 3 & 0 & 3 & 0 & 0 & 6 & 14 & 3 & 5 & 1 & 0 & 1 & 6 \\
\hline Shape concern & 79. Shape influenced self-judgement & 14 & 2 & 5 & 1 & 2 & 1 & 5 & 16 & 1 & 6 & 1 & 2 & 1 & 3 \\
\hline Shape concern & 82. Dissatisfaction with shape & 6 & 9 & 3 & 4 & 2 & 1 & 5 & 9 & 4 & 2 & 4 & 5 & 0 & 6 \\
\hline Shape concern & 83. Uncomfortable seeing body & 11 & 6 & 4 & 1 & 2 & 2 & 4 & 10 & 6 & 6 & 0 & 4 & 1 & 3 \\
\hline Shape concern & 84. Uncomfortable having others see body & 14 & 4 & 2 & 4 & 1 & 0 & 5 & 13 & 4 & 5 & 0 & 2 & 2 & 4 \\
\hline Weight concern & 15. Difficulty concentrating due to shape or weight concern & 24 & 3 & 0 & 0 & 0 & 0 & 3 & 24 & 1 & 2 & 1 & 1 & 0 & 1 \\
\hline Weight concern & 19. Strong weight loss desire & 8 & 4 & 4 & 1 & 1 & 0 & 12 & 6 & 6 & 1 & 2 & 0 & 0 & 15 \\
\hline Weight concern & 78. Weight influenced self-judgement & 12 & 4 & 3 & 2 & 3 & 1 & 5 & 15 & 3 & 5 & 1 & 0 & 2 & 4 \\
\hline Weight concern & 80. Upset if asked to weigh self once/wk for $4 \mathrm{wk}$ & 9 & 4 & 1 & 4 & 1 & 2 & 9 & 13 & 5 & 3 & 1 & 3 & 1 & 4 \\
\hline Weight concern & 81. Dissatisfaction with weight & 9 & 2 & 1 & 5 & 5 & 1 & 7 & 6 & 3 & 5 & 3 & 4 & 4 & 5 \\
\hline Eating concern & 14. Difficulty concentrating due to food intake & 30 & 0 & 0 & 0 & 0 & 0 & 0 & 30 & 0 & 0 & 0 & 0 & 0 & 0 \\
\hline Eating concern & 16. Days fearing out of control eating & 13 & 5 & 3 & 0 & 1 & 1 & 7 & 10 & 5 & 2 & 0 & 1 & 1 & 11 \\
\hline Eating concern & 75. Days eaten in secret & 26 & 3 & 0 & 1 & 0 & 0 & 0 & 25 & 3 & 1 & 0 & 0 & 0 & 1 \\
\hline Eating concern & 76. Proportion of times felt guilty & 14 & 6 & 2 & 3 & 0 & 0 & 5 & 12 & 9 & 2 & 1 & 2 & 2 & 2 \\
\hline Restraint for weight control & 1. Days limiting food to avoid weight gain & 20 & 4 & 2 & 2 & 0 & 1 & 1 & 18 & 4 & 2 & 2 & 1 & 0 & 3 \\
\hline Restraint for weight control & 3. Days w/o eating to avoid weight gain & 29 & 1 & 0 & 0 & 0 & 0 & 0 & 27 & 3 & 0 & 0 & 0 & 0 & 0 \\
\hline Restraint for weight control & 5. Days excluded liked foods to avoid weight gain & 21 & 3 & 1 & 0 & 0 & 1 & 4 & 18 & 4 & 2 & 2 & 0 & 2 & 2 \\
\hline Restraint for weight control & 8. Follow diet rules to avoid weight gain & 20 & 2 & 0 & 0 & 1 & 1 & 6 & 13 & 4 & 0 & 0 & 0 & 4 & 9 \\
\hline Restraint for weight control & 11. Days desiring empty stomach to avoid weight gain & 23 & 3 & 1 & 1 & 0 & 0 & 2 & 21 & 4 & 0 & 1 & 1 & 1 & 2 \\
\hline Restraint to avoid physical discomfort & 2. Days limiting food to avoid physical discomfort & 20 & 7 & 0 & 0 & 0 & 0 & 3 & 16 & 7 & 2 & 0 & 3 & 0 & 2 \\
\hline Restraint to avoid physical discomfort & 4. Days w/o eating to avoid physical discomfort & 29 & 1 & 0 & 0 & 0 & 0 & 0 & 28 & 2 & 0 & 0 & 0 & 0 & 0 \\
\hline Restraint to avoid physical discomfort & 6. Days excluded liked foods to avoid physical discomfort & 19 & 6 & 1 & 1 & 0 & 0 & 3 & 19 & 6 & 1 & 3 & 0 & 0 & 1 \\
\hline Restraint to avoid physical discomfort & 9. Follow diet rules to avoid physical discomfort & 24 & 0 & 0 & 0 & 0 & 0 & 6 & 18 & 3 & 0 & 0 & 0 & 3 & 6 \\
\hline Restraint to avoid physical discomfort & $\begin{array}{l}\text { 12. Days desiring empty stomach to avoid } \\
\text { physical discomfort }\end{array}$ & 23 & 4 & 0 & 0 & 0 & 0 & 3 & 22 & 3 & 1 & 0 & 0 & 1 & 3 \\
\hline Purging for weight control & 46. Vomit to lose weight or avoid weight gain & 29 & 1 & 0 & 0 & 0 & 0 & 0 & 29 & 0 & 0 & 1 & 0 & 0 & 0 \\
\hline Purging for weight control & $\begin{array}{l}\text { 48. Chewed food/spit wo swallow to lose weight/avoid } \\
\text { weight gain }\end{array}$ & 28 & 1 & 0 & 1 & 0 & 0 & 0 & 29 & 1 & 0 & 0 & 0 & 0 & 0 \\
\hline Purging for weight control & 50. Upset after chewing food or spit out w/o swallow & 30 & 0 & 0 & 0 & 0 & 0 & 0 & 29 & 0 & 1 & 0 & 0 & 0 & 0 \\
\hline Purging for weight control & $\begin{array}{l}\text { 63. Days ruminated food to lose weight or avoid } \\
\text { gaining weight }\end{array}$ & 30 & 0 & 0 & 0 & 0 & 0 & 0 & 30 & 0 & 0 & 0 & 0 & 0 & 0 \\
\hline
\end{tabular}


Table 1. Cont.

\begin{tabular}{|c|c|c|c|c|c|c|c|c|c|c|c|c|c|c|c|}
\hline \multirow[b]{2}{*}{ Category } & \multirow[b]{2}{*}{ Item } & \multicolumn{7}{|c|}{ Interview } & \multicolumn{7}{|c|}{ Questionnaire } \\
\hline & & 0 & 1 & 2 & 3 & 4 & 5 & 6 & 0 & 1 & 2 & 3 & 4 & 5 & 6 \\
\hline Purging for weight control & 65. Upset when ruminated food & 29 & 0 & 0 & 0 & 0 & 0 & 1 & 30 & 0 & 0 & 0 & 0 & 0 & 0 \\
\hline Purging for weight control & 66. Take laxatives to lose weight or avoid gaining weight & 30 & 0 & 0 & 0 & 0 & 0 & 0 & 29 & 0 & 1 & 0 & 0 & 0 & 0 \\
\hline Purging for weight control & 68. Take diuretics to lose weight or avoid gaining weight & 30 & 0 & 0 & 0 & 0 & 0 & 0 & 30 & 0 & 0 & 0 & 0 & 0 & 0 \\
\hline Purging for weight control & 70. Driven or compulsive exercise to lose weight & 29 & 1 & 0 & 0 & 0 & 0 & 0 & 26 & 2 & 1 & 0 & 0 & 0 & 1 \\
\hline Purging for weight control & 85. Vomited in last $4 \mathrm{wks}$, how upset about it & 30 & 0 & 0 & 0 & 0 & 0 & 0 & 30 & 0 & 0 & 0 & 0 & 0 & 0 \\
\hline Purging to avoid physical discomfort & 47. Vomit to avoid physical discomfort & 25 & 3 & 1 & 0 & 1 & 0 & 0 & 27 & 2 & 0 & 1 & 0 & 0 & 0 \\
\hline Purging to avoid physical discomfort & $\begin{array}{l}\text { 49. Chewed food/spit w/o swallow to avoid } \\
\text { physical discomfort }\end{array}$ & 25 & 3 & 0 & 2 & 0 & 0 & 0 & 26 & 3 & 0 & 1 & 0 & 0 & 0 \\
\hline Purging to avoid physical discomfort & 64. Days ruminated food to avoid physical discomfort & 27 & 1 & 0 & 0 & 1 & 0 & 1 & 29 & 0 & 0 & 0 & 1 & 0 & 0 \\
\hline Purging to avoid physical discomfort & 67. Take laxatives to avoid physical discomfort & 27 & 2 & 0 & 0 & 1 & 0 & 0 & 27 & 2 & 1 & 0 & 0 & 0 & 0 \\
\hline Purging to avoid physical discomfort & 69. Take diuretics to avoid physical discomfort & 30 & 0 & 0 & 0 & 0 & 0 & 0 & 30 & 0 & 0 & 0 & 0 & 0 & 0 \\
\hline
\end{tabular}

a Table of frequencies for each item, format, and response. $\mathrm{N}=30$. See Appendix A for full text of questions.

Table 2. Comparison of responses to items in the interview and questionnaire.

\begin{tabular}{|c|c|c|c|c|c|c|c|c|c|c|c|c|}
\hline Category $^{d}$ & Item & 0,0 & 0,1 & 1,0 & 1,1 & $\begin{array}{c}\text { Concordant } \\
(\%)\end{array}$ & $\begin{array}{l}\text { Binomial }^{b} \\
\quad \text { Con } p\end{array}$ & $\begin{array}{l}\text { Binomial }^{c} \\
\quad \text { Dis } p\end{array}$ & $x^{2}$ & $\chi^{2} p$ & $\mathrm{C}$ & $\kappa$ \\
\hline Shape concern & $\begin{array}{l}\text { 13. Days desiring } \\
\text { flat stomach }\end{array}$ & $13(43 \%)$ & $3(10 \%)$ & $0(0 \%)$ & $14(47 \%)$ & $90 \%$ & $<0.0001$ & 0.08 & 20.07 & $<0.0001$ & 0.63 & 0.80 \\
\hline Shape concern & 17. Fear of wt gain & $3(10 \%)$ & $1(3 \%)$ & $1(3 \%)$ & $25(83 \%)$ & $93 \%$ & $<0.0001$ & 1.00 & 15.19 & $<0.0001$ & 0.58 & 0.71 \\
\hline Shape concern & 18. Feeling fat & $14(47 \%)$ & $0(0 \%)$ & $4(13 \%)$ & $12(40 \%)$ & $87 \%$ & $<0.0001$ & 0.05 & 17.50 & $<0.0001$ & 0.61 & 0.74 \\
\hline Shape concern & $\begin{array}{l}\text { 79. Shape influenced } \\
\text { self-judgement }\end{array}$ & $12(40 \%)$ & $4(13 \%)$ & $2(7 \%)$ & $12(40 \%)$ & $80 \%$ & 0.001 & 0.41 & 11.06 & 0.001 & 0.52 & 0.60 \\
\hline Shape concern & 82. Dissat with shape & $4(13 \%)$ & $5(17 \%)$ & $2(7 \%)$ & $19(63 \%)$ & $76 \%$ & 0.004 & 0.26 & 4.80 & 0.028 & 0.37 & 0.39 \\
\hline Shape concern & 83. Uncomf seeing body & $9(30 \%)$ & $1(3 \%)$ & $2(7 \%)$ & $18(60 \%)$ & $90 \%$ & $<0.0001$ & 0.56 & 18.37 & $<0.0001$ & 0.62 & 0.78 \\
\hline Shape concern & $\begin{array}{l}\text { 84. Uncomf having others } \\
\text { see body }\end{array}$ & $10(33 \%)$ & $3(10 \%)$ & $4(13 \%)$ & $13(43 \%)$ & $76 \%$ & 0.004 & 0.71 & 8.44 & 0.004 & 0.47 & 0.53 \\
\hline Weight concern & $\begin{array}{l}\text { 15. Diff conc due to shape or } \\
\text { wt concern }\end{array}$ & $23(77 \%)$ & $1(3 \%)$ & $1(3 \%)$ & $5(17 \%)$ & $94 \%$ & $<0.0001$ & 1.00 & 18.80 & $<0.0001$ & 0.62 & 0.79 \\
\hline Weight concern & 19. Strong wt loss desire & $6(20 \%)$ & $0(0 \%)$ & $2(7 \%)$ & $22(73 \%)$ & $93 \%$ & $<0.0001$ & 0.16 & 20.63 & $<0.0001$ & 0.64 & 0.81 \\
\hline
\end{tabular}


Table 2. Cont.

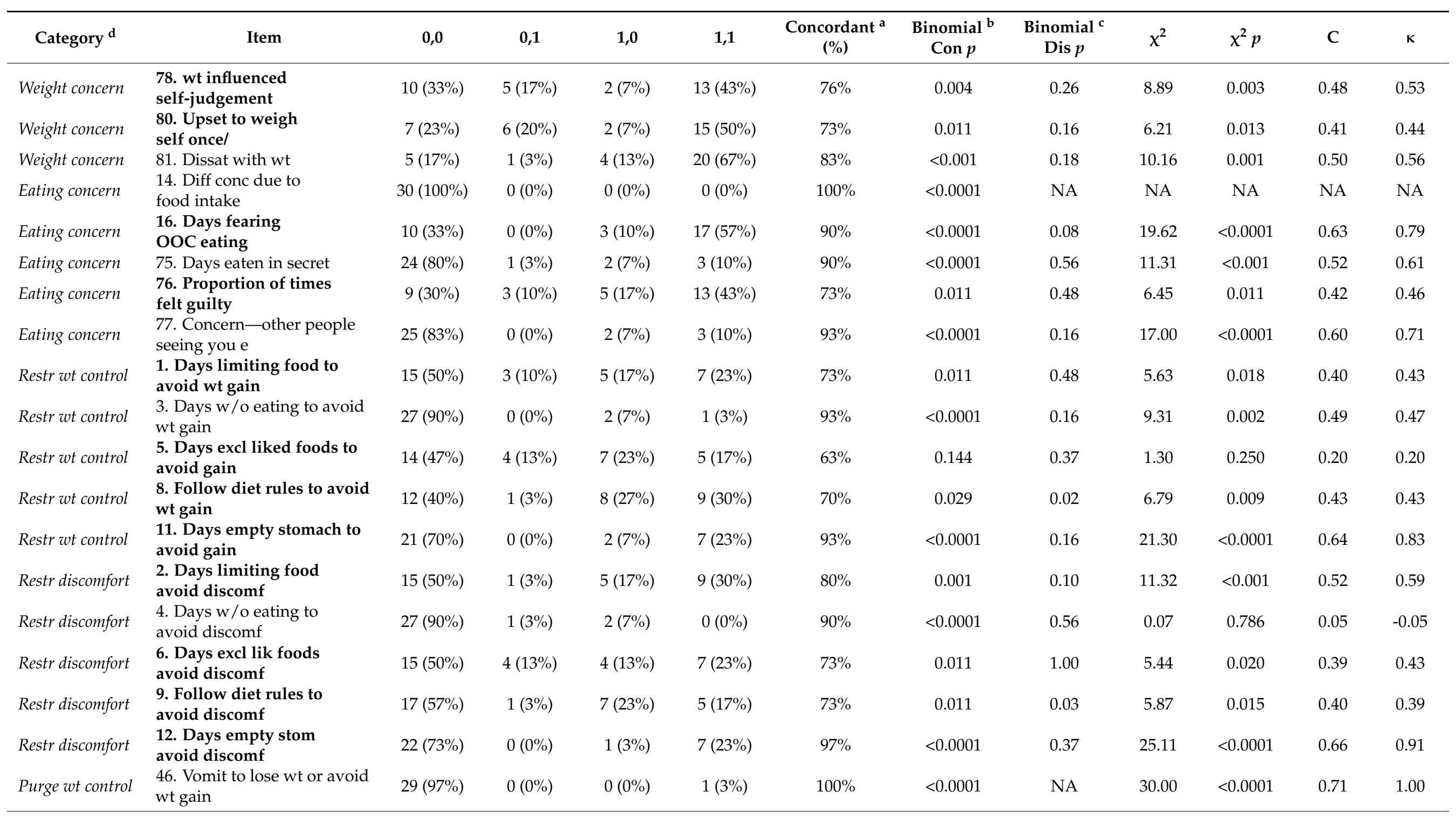


Table 2. Cont.

\begin{tabular}{|c|c|c|c|c|c|c|c|c|c|c|c|c|}
\hline Category $^{d}$ & Item & 0,0 & 0,1 & 1,0 & 1,1 & $\begin{array}{c}\text { Concordant } \\
(\%)\end{array}$ & $\begin{array}{l}\text { Binomial } \\
\quad \text { Con } p\end{array}$ & $\begin{array}{l}\text { Binomial }^{\mathrm{c}} \\
\quad \text { Dis } p\end{array}$ & $x^{2}$ & $x^{2} p$ & $\mathrm{C}$ & $\kappa$ \\
\hline Purge wt control & $\begin{array}{l}\text { 48. Chewed food/spit } \\
\text { wo swallow }\end{array}$ & $28(93 \%)$ & $1(3 \%)$ & $0(0 \%)$ & $1(3 \%)$ & $97 \%$ & $<0.0001$ & 0.32 & 14.48 & 0.0001 & 0.57 & 0.65 \\
\hline Purge wt control & $\begin{array}{l}\text { 50. Upset after chewing food } \\
\text { or spit out }\end{array}$ & $29(97 \%)$ & $0(0 \%)$ & $1(3 \%)$ & $0(0 \%)$ & $97 \%$ & $<0.0001$ & NA & NA & NA & NA & NA \\
\hline Purge wt control & $\begin{array}{l}\text { 63. Days ruminated food to } \\
\text { lose wt }\end{array}$ & $30(100 \%)$ & $0(0 \%)$ & $0(0 \%)$ & $0(0 \%)$ & $100 \%$ & $<0.0001$ & NA & NA & NA & NA & NA \\
\hline Purge wt control & $\begin{array}{l}65 . \text { Upset when } \\
\text { ruminated food }\end{array}$ & $29(97 \%)$ & $1(3 \%)$ & $0(0 \%)$ & $0(0 \%)$ & $97 \%$ & $<0.0001$ & NA & NA & NA & NA & NA \\
\hline Purge wt control & $\begin{array}{l}\text { 66. Take laxatives to } \\
\text { lose/avoid gaining }\end{array}$ & $29(97 \%)$ & $0(0 \%)$ & $1(3 \%)$ & $0(0 \%)$ & $97 \%$ & $<0.0001$ & NA & NA & NA & NA & NA \\
\hline Purge wt control & $\begin{array}{l}\text { 68. Take diuretics to } \\
\text { lose/avoid gaining }\end{array}$ & $30(100 \%)$ & $0(0 \%)$ & $0(0 \%)$ & $0(0 \%)$ & $100 \%$ & $<0.0001$ & NA & NA & NA & NA & NA \\
\hline Purge wt control & 70. Driven exercise to lose wt & $26(87 \%)$ & $0(0 \%)$ & $3(10 \%)$ & $1(3 \%)$ & $90 \%$ & $<0.0001$ & 0.08 & 6.72 & 0.010 & 0.43 & 0.36 \\
\hline Purge wt control & $\begin{array}{l}\text { 85. Vomited in last } 4 \text { wks, } \\
\text { upset about }\end{array}$ & $30(100 \%)$ & $0(0 \%)$ & $0(0 \%)$ & $0(0 \%)$ & $100 \%$ & $<0.0001$ & NA & NA & NA & NA & NA \\
\hline $\begin{array}{l}\text { Purge avoi } \\
\text { discomf }\end{array}$ & $\begin{array}{l}\text { 47. Vomit to avoid } \\
\text { phys discomf }\end{array}$ & $25(83 \%)$ & $2(7 \%)$ & $0(0 \%)$ & $3(10 \%)$ & $93 \%$ & $<0.0001$ & 0.16 & 17.00 & $<0.0001$ & 0.60 & 0.71 \\
\hline $\begin{array}{l}\text { Purge avoi } \\
\text { discomf }\end{array}$ & 64. Days ruminated food & $27(90 \%)$ & $2(7 \%)$ & $0(0 \%)$ & $1(3 \%)$ & $93 \%$ & $<0.0001$ & 0.16 & 9.31 & 0.002 & 0.49 & 0.47 \\
\hline $\begin{array}{l}\text { Purge avoi } \\
\text { discomf }\end{array}$ & $\begin{array}{l}\text { 67. Take laxatives avoid } \\
\text { phys discomf }\end{array}$ & $27(90 \%)$ & $0(0 \%)$ & $0(0 \%)$ & $3(10 \%)$ & $100 \%$ & $<0.0001$ & NA & 30.00 & $<0.0001$ & 0.71 & 1.00 \\
\hline $\begin{array}{l}\text { Purge avoi } \\
\text { discomf }\end{array}$ & $\begin{array}{l}\text { 69. Take diuretics avoid } \\
\text { phys discomf }\end{array}$ & $30(100 \%)$ & $0(0 \%)$ & $0(0 \%)$ & $0(0 \%)$ & $100 \%$ & $<0.0001$ & NA & NA & NA & NA & NA \\
\hline
\end{tabular}

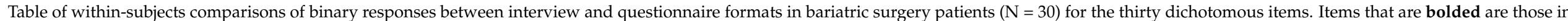

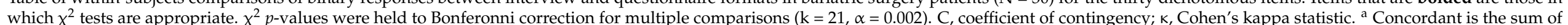

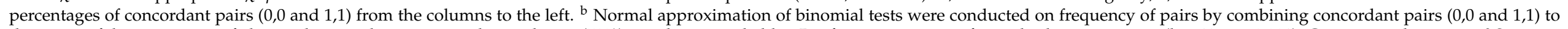

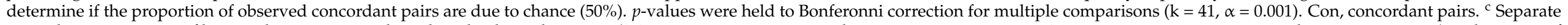

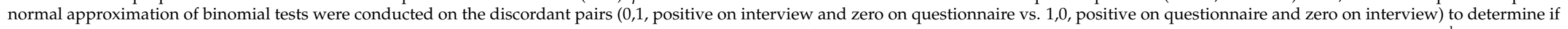

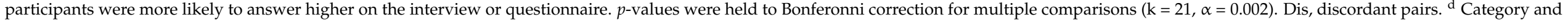
item are abbreviated. Full text can be found in Table 1 and Appendix A. 


\subsubsection{Spearman Rank-Order Correlations}

For items that met ordinal criteria, Spearman rank order correlations were run on the scaled scores (0-6) from the interview and questionnaire to measure the strength of association between the two formats in a more precise manner than by the Chi-square test.

\section{Results}

\subsection{Demographics}

Participants were mostly female post-bariatric patients (80\%). The mean age at the interview was $45.7 \mathrm{y} \pm 8.5 \mathrm{SD}$ and the mean time post-surgery was $1.8 \mathrm{y} \pm 0.5 \mathrm{SD}$. The mean body mass index (BMI) was $40.5 \mathrm{~kg} / \mathrm{m}^{2} \pm 4.8 \mathrm{SD}$ before surgery and $28.1 \mathrm{~kg} / \mathrm{m}^{2} \pm 5.2 \mathrm{SD}$ at the time of interview.

\subsection{Distributions and Frequency of Response to Items in the Questionnaire and Interview}

Distributions of responses were similar for the two formats, but they did not segregate into two distinct types, and none of them were normal. Figure 1 shows a plot of the sum, or number, of participants that reported in the intermediate range $(2,3$, or 4$)$ across all scored items in both formats. As per the ordinal criteria in Section 2.4.1, only two items of all items in the interview (Q81: Dissatisfaction with weight; Q82: Dissatisfaction with shape), and four from the questionnaire (Q79: Shape influenced self-judgement; Q81; Q82; Q83: Uncomfortable seeing body) were classified as ordinal (Figure 1).

\section{Interview}

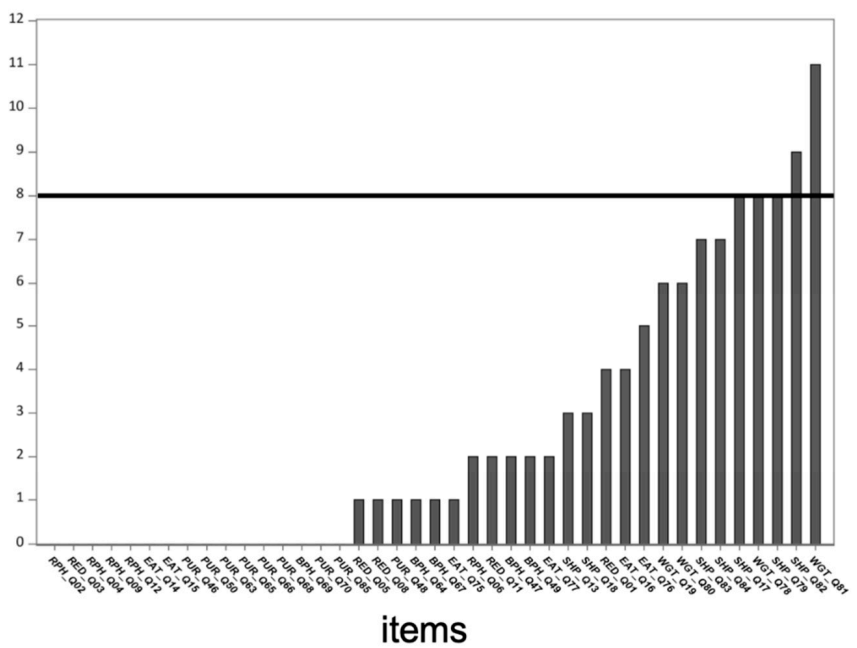

\section{Questionnaire}

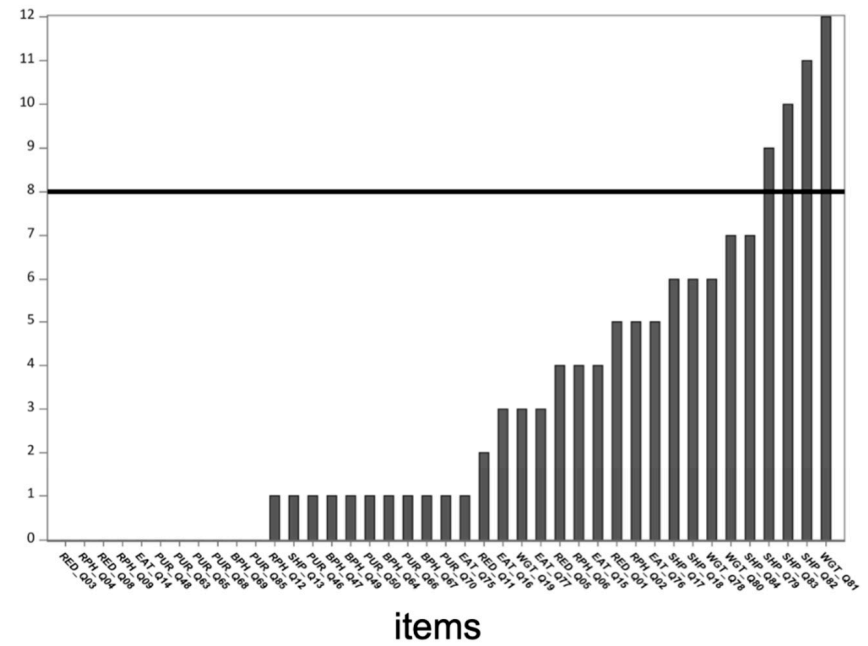

Figure 1. Graphical illustration of intermediate scores across items in the interview and questionnaire. Graph showing the number of participants $(n=30)$ intermediate scores (between 2 and 4$)$ in the interview and questionnaire. The bold horizontal lines (at the 8 tick on the ordinate axis) are the cut offs between ordinal and not ordinal, with any items with bars breaching this line being considered ordinal. Items on the abscissa are in ascending order, for each format. The first three letters of each item correspond with a behavior/symptom category-RED, restraint for weight control; RPH, restraint to avoid physical discomfort; BPH, purging to avoid physical discomfort; PUR, purging for weight control; EAT, eating concern; WGT, weight concern; SHP, shape concern. See Appendix A for the full text of each item.

Conversely, almost all responses to purging-related items were zero. In all thirty participants, there were only eight non-zero responses for the fourteen purging-related items (Figure 1).

Intermediate response frequencies (i.e., responses of 2,3, or 4), among the remaining dichotomous items, gradually increased across items, with no sharp breaks (Figure 1). Items that comprised the restraint for weight control, restraint to avoid physical discomfort, purging for weight control, and purging to avoid physical discomfort categories were more dichotomous than items that comprise the eating concern, weight concern, and shape 
concern categories (Figure 1). Furthermore, the items that comprise the eating concern, weight concern, and shape concern categories had higher reported behavior than not, i.e., ten or more patients reported the behavior (Table 1).

The higher the number of intermediate scores, the more likely that rank order correlations should be performed, which can be determined from both Table 1 (for exact responses to each item) and Figure 1 (for sum of response frequencies in the intermediate range). With the numbers of responses in the intermediate range as a gauge of an ordinal responding pattern (Figure 1), the largest number of ordinal responses was only twelve participants, i.e., less than half the sample, for all items.

\subsection{Binomial Tests}

\subsubsection{Tests of Agreement}

Before Bonferroni correction (Table 2, binomial on concordant pairs, $p<0.05$ ), agreement of responses on the two formats was significant for all items except Q5: Days excluding liked foods to avoid weight gain $(p>0.05)$. After Bonferroni correction $(\mathrm{k}=41$, $\alpha=0.001$ ), the following ten items were not significant, although their percent concordance was still relatively high (73-76\%, Table 2): Q1: Days limiting food to avoid weight gain; Q5, Q6: Days excluding liked foods to avoid physical discomfort; Q8: Follow diet rules to avoid weight gain; Q9: Follow diet rules to avoid physical discomfort; Q76: Proportion of times felt guilty; Q78: weight influenced self-judgement; Q80: Upset if asked to weigh self once/wk for $4 \mathrm{wk}, \mathrm{Q} 82 ; \mathrm{Q} 84$ : Uncomfortable having others see body $(p>0.001$, Table 2). Given that the confidence interval for the percent concordance is $5.36(\sqrt{(n=30) *(p=.50) *(q=.50)} \times 1.96=5.36)$, these ten items with slightly lower percent concordances are likely not significantly different.

\subsubsection{Tests on Discordant Pairs $(0,1$ and 1,0$)$}

After Bonferroni correction $(\mathrm{k}=21, \alpha=0.002)$, there were no significant differences between the discordant pairs $(p<0.002$, Table 2$)$. Consequently, there was no significant difference between the number of positive responses on the interview compared to the questionnaire for any item.

\subsection{Tests of Association}

\subsubsection{Chi-Squared Tests}

Although $\chi^{2}$ tests were invalid for twelve items (see Section 2.4.4 for $\chi^{2}$ test criteria, Table 2), for the remaining twenty-one items, the $\chi^{2}$ was significant for all (C's: 0.37-0.66, K's: $0.39-0.91, p>0.05$, Table 2) but one of them (Q5, $p>0.05$, Table 2). After Bonferroni correction $(k=21, \alpha=0.002)$, the non-significant items $(p>0.002)$ from the $\chi^{2}$ tests were the same as those in the first binomial tests of agreement (see Section 3.3.1).

\subsubsection{Spearman Rank Order Correlations on Ordinal Items}

The four ordinal items (see Section 3.2) were significantly correlated between formats $(p<0.05$, Figure $2 \mathrm{~A}-\mathrm{H})$ even with Bonferroni correction $(\mathrm{k}=4, \alpha=0.0125)$. These items addressed feelings of dissatisfaction with shape and weight, self-judgment, and being uncomfortable with seeing your body. Neither of the slopes were significantly different from 1, nor were the intercepts significantly different from zero. 


\section{A Q79 Shape-influenced self-judgment}

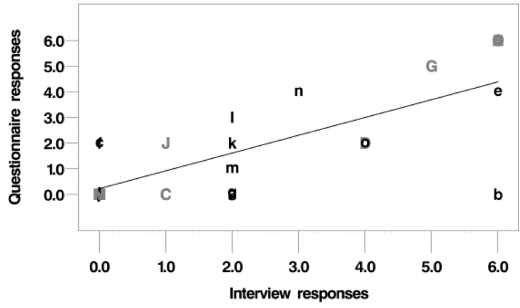

\section{Q81 Dissatisfaction with weight}

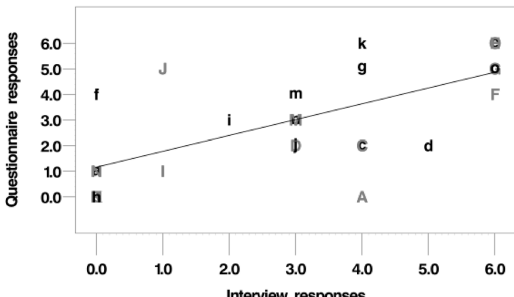

\section{E Q82 Dissatisfaction with shape}

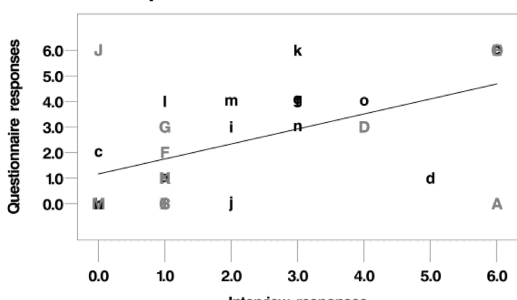

\section{G Q83 Uncomfortable seeing body}

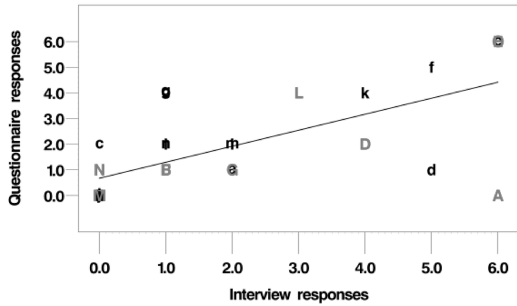

B Q79 Shape-influenced self-judgment

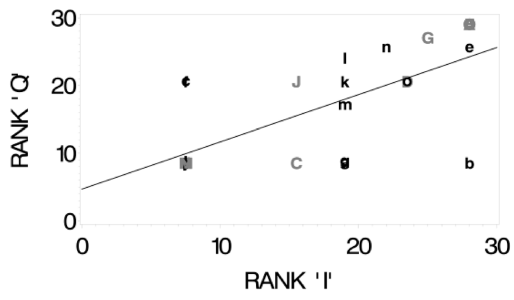

\section{Q81 Dissatisfaction with weight}

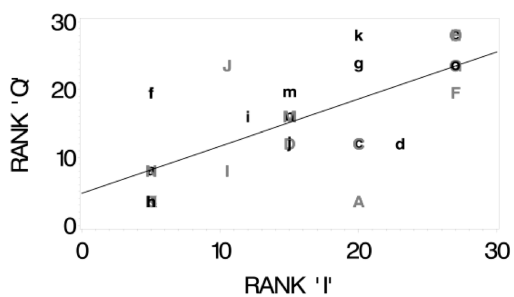

\section{F Q82 Dissatisfaction with shape}

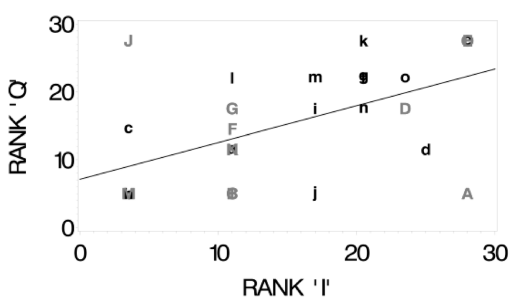

\section{H Q83 Uncomfortable seeing body}

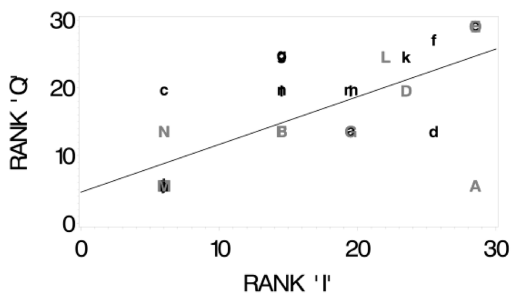

Figure 2. Panel of Pearson linear regression and Spearman rank order correlations plots. (A,C,E,G) are Pearson linear regression plots with scaled score response (0-6) from questionnaire (ordinate) regressed from interview (abscissa). Note: Since the distributions of response for these items are not normal, Pearson linear regression is not appropriate, and the presentation of these plots are for visual aid. (B) $\left(\mathrm{R}^{2}=0.72, p<0.001\right)$, (D) (R2 = 0.69, $\left.p<0.001\right)$, (F) (R2 $\left.=0.54, p<0.002\right)$, and $(\mathbf{H})(\mathrm{R} 2=0.70, p<0.001)$ are Spearman rank order correlation plots with the rank of questionnaire response (ordinate) and the rank of interview response (abscissa). Item number for (A-H) noted below the title of each plot. All items significant after Bonferroni correction $(k=4, \alpha=0.0125)$. See Appendix A for the full text of each item.

\section{Discussion}

To the best of our knowledge, this is the first study that aims to assess the consistency in response between the EDE-BSV in interview and questionnaire formats in post-bariatric surgery patients. In addition, an important and novel feature of this comparison that is 
different from those in the literature $[2,8-18]$ is the careful analysis of every item across the two formats of assessment.

Previous attempts to compare the EDE interview and EDE-Q were conducted among patients with eating disorders [9-11,13,15-18]; in community samples [8,14]; among bariatric candidates and patients $[2,12]$. The results in these reports did not reveal either the distribution of the responses on individual items, nor the agreement and associations among the items. However, they have combined items in ways that are not fully validated for combinations of non-normally distributed, and particularly, items with a dichotomous distribution. The procedures used in our study relied on distribution-free assumptions. This report, which illustrated consistency of response between the EDE-BSV and EDABS-Q, is the first in a series of planned reports that will further appraise the psychometric quality of the EDABS-Q (reproducibility, construct, criterion, and predictive validity). Thus, further research is needed to complete the findings of the current research.

The current study found that only $2 \%$ of all the 30 participants, reported to have any purging-related behavior. These findings are in line with previous studies that found that purging episodes are not a common behavior among this population [2,19]. Most purging-type behaviors after bariatric surgery are related to physical discomfort due to the surgery $[20,21]$. However, cases of self-induced vomiting related to weight and shape concerns following surgery are rare, and prevalence data have been largely unavailable $[7,22]$. We might have captured a higher prevalence of purging related to physical discomfort if our sample were closer to the time of the surgery in which this behavior is more likely to occur [20]. On the other hand, perhaps we would have captured a higher prevalence in purging related to weight control (especially those due to "intense exercise") years after the surgery when weight regain starts and the need to compensate might be higher [19].

It should be noted that we also determined specific purging types that are related to post bariatric patients (chewing and spitting and rumination to avoid weight gain or to avoid physical discomfort). Even with a low prevalence of these behaviors, we found a high and significant agreement (93-97\%), but because of the low prevalence, these results should be interpreted with caution.

Overall, there was strong agreement between formats across almost every item. Even for the items that did not significantly agree, with highly restrictive criteria, the percentage of responses that agreed on the two formats was close to $75 \%$ (50\% would be chance). Given the small sample size, and the standard error $(=\sqrt{N p q}$, where $\mathrm{N}$ is the number of observations (30) and $p$ and $q$ are chance probabilities of same and different responses $(=0.5)$, respectively) of any percentage of $\pm \frac{5.3}{30}=17.67 \%$, there is virtually perfect agreement within limits of confidence.

Previous studies that compared the EDE to the EDE-Q have not reported either the distribution of the responses on individual items, nor the agreement and associations among the items, but rather the relationship between the mean score of each subscales and total scores, which makes it difficult to compare to our results. In addition, the only study that compared the EDE and EDEQ with post-surgery bariatric patients, and not bariatric surgery candidates (before surgery), was de Zwaan et al. (2004). Even though de Zwaan and colleagues did not report associations and agreement between items, they likewise found a high percentage of agreement between subscales (about $90 \%$ agreement in eating, weight and shape concern, and $62 \%$ in restraint) and found significant correlations in all the subscales. The authors explain the weaker agreement in the restraint subscale by the possibility that subjects might have included the restraint they experienced due to their gastric surgery rather than only the restriction to avoid weight gain. In our study, restraint questions were separated to into two categories (as in the EDE-BSV) in order to clarify it for the subjects. Items of the restraint category highly agreed for most of the items (73-93\% and only one item was $63 \%$ ), and two items that did not reach significance after highly restricted criteria. These items might still need to be modified or rewritten in a clearer way for this population in order to be suitable as a self-report. However, the rest of the items that did not meet criteria for significant agreement or association do not appear to 
be systematically different in any clinically meaningful way from the other items, and it is most likely that not reaching statistical significance is simply attributable to variability inherent in a small sample.

There are three major strengths: (1) the convenience of a self-report questionnaire for assessment, research and clinical purposes; (2) its significance to a very specific population, i.e., post-bariatric surgical patients; (3) rigorous data analyses appropriate for specific types of questions applicable for this population, which increase confidence that the self-report questionnaire is an adequate substitute of the interview. Consequently, we can also pinpoint which items should be modified for the next iteration of the EDABS-Q. Another strength is that the study took place in Israel, which has a very diverse population, and comprised a variety of socioeconomic classes, cultures, and religions in a high-quality public health system. However, we suggest replication of this study in other populations and countries.

Potential limitations should be considered because of the small sample size. In addition, the time period chosen was between 1 and 2 years following the surgery. This stage after the operation may be too early to observe specific eating pathologies especially among items that address purging to control weight. We have taken the approach of first validating the questionnaire from the interview, because it is more practical to administer the questionnaire to a sufficiently large sample to determine validity of the various items and whether they coalesce into scales and subscales that are similar to the original EDE or different.

\section{Conclusions}

The strong agreement and association between the EDABS-Q and the interview demonstrates that the EDABS-Q is a valid representation of the information obtained in the interview and that it could be used as a substitute for the interview without significant loss of information. There was no evidence from either type of analysis that the interview and questionnaire were systematically different in any way. The EDABS-Q should be a useful alternative for time-consuming clinical interviews for research on post-bariatric surgery patients.

Author Contributions: Conceptualization, I.G., M.H., J.E.M. and Y.L.; data curation, I.G.; formal analysis, H.R.K. and J.D.H.; investigation, I.G.; project administration, Y.L.; validation, H.R.K. and J.D.H.; writing—original draft, I.G. and J.D.H.; writing—review and editing, H.R.K., J.E.M. and Y.L. All authors have read and agreed to the published version of the manuscript.

Funding: Data analysis, interpretation, and manuscript preparation in the United States were supported by NIH grant R01DK108643 Mechanisms Underlying Predictors of Success from Obesity Surgery (HR Kissileff, PI).

Institutional Review Board Statement: The study was conducted according to the guidelines of the Declaration of Helsinki and approved by the Institutional Review Board at Assuta Medical Center, Israel.

Informed Consent Statement: Informed consent was obtained from all subjects involved in the study.

Data Availability Statement: Data available on request due to restrictions eg privacy or ethical. The data presented in this study are available on request from the corresponding author. The data are not publicly available due to patients privacy.

Acknowledgments: The authors wish a special thanks to C. Fairburn and his group for his permission to use and adapt his well-known EDEQ for post-bariatric patients.

Conflicts of Interest: The authors declare no conflict of interest. 


\section{Appendix A}

Table A1. Questions used in the Eating Disorders after Bariatric Surgery Questionnaire ${ }^{1}$.

\begin{tabular}{lcl}
\hline Category & Item Number & Prompt \\
\hline Shape concern & Q13 & On how many days have you had a definite desire to have a totally flat stomach? \\
\hline Shape concern & Q15 & $\begin{array}{l}\text { Has thinking about shape or weight made it very difficult to concentrate on things } \\
\text { you are interested in (for example, working, following a conversation, or reading)? }\end{array}$ \\
\hline Shape concern & Q17 & Have you had a definite fear that you might gain weight? \\
\hline Shape concern & Q18 & Have you felt fat? \\
\hline Shape concern & Q79 & Has your shape influenced how you think about (judge) yourself as a person? \\
\hline Shape concern & Q82 & How dissatisfied have you been with your shape? \\
\hline & Q83 concern & $\begin{array}{l}\text { How uncomfortable have you felt seeing your body (for example, seeing your } \\
\text { shape in the mirror, in a shop window reflection, while undressing, or taking a } \\
\text { bath or shower)? }\end{array}$ \\
\hline
\end{tabular}

\begin{tabular}{lll}
$\begin{array}{l}\text { Shape concern } \\
\text { Weight concern }\end{array}$ & Q15 & $\begin{array}{l}\text { How uncomfortable have you felt about others seeing your shape or figure (for } \\
\text { example, in communal changing rooms, when swimming, or wearing } \\
\text { tight clothes)? }\end{array}$ \\
\hline $\begin{array}{l}\text { Weight concern } \\
\text { Weight concern }\end{array}$ & $\begin{array}{l}\text { Has thinking about shape or weight made it very difficult to concentrate on things } \\
\text { you are interested in (for example, working, following a conversation, or reading)? }\end{array}$ \\
\hline Weight concern & Q78 & Have you had a strong desire to lose weight? \\
\hline Weight concern & Q80 & $\begin{array}{l}\text { How much would it have upset you if you had been asked to weigh yourself once } \\
\text { a week for the next four weeks? }\end{array}$ \\
\hline
\end{tabular}

Has thinking about food, eating, or calories made it very difficult to concentrate on

Eating concern Q14 things you are interested in (for example, working, following a conversation, or reading)?

\begin{tabular}{lll}
\hline Eating concern & Q16 & $\begin{array}{l}\text { On how many days have you strongly feared that you would lose control } \\
\text { over eating? }\end{array}$ \\
\hline Eating concern & Q75 & $\begin{array}{l}\text { Over the past four weeks (28 days), on how many days have you eaten in secret } \\
\text { (i.e., furtively)? [Do not count episodes of binge eating] }\end{array}$ \\
\hline Eating concern & Q76 & $\begin{array}{l}\text { On what proportion of the times that you have eaten have you felt guilty (felt that } \\
\text { you've done wrong) because of its effect on your shape or weight? [Do not count } \\
\text { episodes of binge eating] }\end{array}$ \\
\hline Eating concern & Q77 & $\begin{array}{l}\text { How concerned have you been about other people seeing you eat? [Do not count } \\
\text { episodes of binge eating] }\end{array}$ \\
\hline Restraint for weight control & Q01 & $\begin{array}{l}\text { On how many days have you deliberately tried to limit the amount of food you } \\
\text { ate, regardless of whether or not you were successful, for any of the following } \\
\text { reasons? (a) To lose weight or avoid gaining weight }\end{array}$ \\
\hline Restraint for weight control & $\begin{array}{l}\text { Over the past four weeks (28 days), on how many days have you gone for long } \\
\text { periods of time (8 waking hours or more) without eating anything at all for any of } \\
\text { the following reasons? (a) To lose weight or avoid gaining weight }\end{array}$ \\
\hline Restraint for weight control & Q05 & $\begin{array}{l}\text { Over the past four weeks (28 days), on how many days have you tried to exclude } \\
\text { from your diet any foods that you like, regardless of whether or not you were } \\
\text { successful, for any of the following reasons? (a) To lose weight or avoid } \\
\text { gaining weight }\end{array}$ \\
\hline Qestraint for weight control & $\begin{array}{l}\text { Over the past four weeks (28 days), on how many days have you tried to follow } \\
\text { definite rules regarding your eating (for example, a calorie limit), regardless of } \\
\text { whether or not you were successful, for any of the following reasons? (a) To lose } \\
\text { weight or avoid gaining weight }\end{array}$ \\
\hline
\end{tabular}


Table A1. Cont.

\begin{tabular}{|c|c|c|}
\hline Category & Item Number & Prompt \\
\hline Restraint for weight control & Q11 & $\begin{array}{l}\text { Over the past four weeks ( } 28 \text { days), on how many days have you had a definite } \\
\text { desire to have an empty stomach for any of the following reasons? (a) To lose } \\
\text { weight or avoid gaining weight b) To avoid physical discomfort }\end{array}$ \\
\hline $\begin{array}{l}\text { Restraint for physical } \\
\text { discomfort }\end{array}$ & Q02 & $\begin{array}{l}\text { On how many days have you deliberately tried to limit the amount of food you } \\
\text { ate, regardless of whether or not you were successful, for any of the following } \\
\text { reasons? (b) To avoid physical discomfort }\end{array}$ \\
\hline $\begin{array}{l}\text { Restraint for physical } \\
\text { discomfort }\end{array}$ & Q04 & $\begin{array}{l}\text { Over the past four weeks ( } 28 \text { days), on how many days have you gone for long } \\
\text { periods of time ( } 8 \text { waking hours or more) without eating anything at all for any of } \\
\text { the following reasons? (b) To avoid physical discomfort }\end{array}$ \\
\hline $\begin{array}{l}\text { Restraint for physical } \\
\text { discomfort }\end{array}$ & Q06 & $\begin{array}{l}\text { Over the past four weeks ( } 28 \text { days), on how many days have you tried to exclude } \\
\text { from your diet any foods that you like, regardless of whether or not you were } \\
\text { successful, for any of the following reasons? (b) To avoid physical discomfort }\end{array}$ \\
\hline $\begin{array}{l}\text { Restraint for physical } \\
\text { discomfort }\end{array}$ & Q09 & $\begin{array}{l}\text { Over the past four weeks ( } 28 \text { days), on how many days have you tried to follow } \\
\text { definite rules regarding your eating (for example, a calorie limit), regardless of } \\
\text { whether or not you were successful, for any of the following reasons? (b) To avoid } \\
\text { physical discomfort }\end{array}$ \\
\hline $\begin{array}{l}\text { Restraint for physical } \\
\text { discomfort }\end{array}$ & Q12 & $\begin{array}{l}\text { Over the past four weeks ( } 28 \text { days), on how many days have you had a definite } \\
\text { desire to have an empty stomach for any of the following reasons? (b) To avoid } \\
\text { physical discomfort }\end{array}$ \\
\hline $\begin{array}{l}\text { Purging to avoid physical } \\
\text { discomfort }\end{array}$ & Q47 & $\begin{array}{l}\text { Over the past four weeks ( } 28 \text { days), on how many days have you made yourself } \\
\text { vomit for any of the following reasons? (b) To avoid physical discomfort }\end{array}$ \\
\hline $\begin{array}{l}\text { Purging to avoid physical } \\
\text { discomfort }\end{array}$ & Q49 & $\begin{array}{l}\text { Over the past four weeks ( } 28 \text { days), on how many days have you purposely } \\
\text { chewed food and spit it out without swallowing it, for any of the following } \\
\text { reasons? (b) To avoid physical discomfort }\end{array}$ \\
\hline $\begin{array}{l}\text { Purging to avoid physical } \\
\text { discomfort }\end{array}$ & Q64 & $\begin{array}{l}\text { Over the past four weeks ( } 28 \text { days), on how many days have you ruminated food; } \\
\text { that is, on purpose, brought food back up again into your mouth and chewed and } \\
\text { swallowed it again, for any of the following reasons? (b) To avoid } \\
\text { physical discomfort }\end{array}$ \\
\hline $\begin{array}{l}\text { Purging to avoid physical } \\
\text { discomfort }\end{array}$ & Q67 & $\begin{array}{l}\text { Over the past four weeks ( } 28 \text { days), on how many days have you taken laxatives } \\
\text { in larger than recommended amounts (including on product labeling) for any of } \\
\text { the following reasons? (b) To avoid physical discomfort }\end{array}$ \\
\hline $\begin{array}{l}\text { Purging to avoid physical } \\
\text { discomfort }\end{array}$ & Q69 & $\begin{array}{l}\text { Over the past four weeks ( } 28 \text { days), on how many days have you taken diuretics } \\
\text { (water pills) in larger than recommended amounts (including recommendations } \\
\text { on product labeling), for any of the following reasons? (b) To avoid } \\
\text { physical discomfort }\end{array}$ \\
\hline Purging for weight control & Q46 & $\begin{array}{l}\text { Over the past four weeks ( } 28 \text { days), on how many days have you made yourself } \\
\text { vomit for any of the following reasons? (a) To lose weight or avoid gaining weight }\end{array}$ \\
\hline Purging for weight control & Q48 & $\begin{array}{l}\text { Over the past four weeks ( } 28 \text { days), on how many days have you purposely } \\
\text { chewed food and spit it out without swallowing it, for any of the following } \\
\text { reasons? (a) To lose weight or avoid gaining weight }\end{array}$ \\
\hline Purging for weight control & Q50 & $\begin{array}{l}\text { If you have purposely chewed food and spit it out without swallowing it, how } \\
\text { distressed or upset have you usually been about this behavior? }\end{array}$ \\
\hline Purging for weight control & Q63 & $\begin{array}{l}\text { Over the past four weeks ( } 28 \text { days), on how many days have you ruminated food; } \\
\text { that is, on purpose, brought food back up again into your mouth and chewed and } \\
\text { swallowed it again, for any of the following reasons? (a) To lose weight or avoid } \\
\text { gaining weight }\end{array}$ \\
\hline Purging for weight control & Q65 & $\begin{array}{l}\text { If you have ruminated food in the past four weeks, how distressed or upset have } \\
\text { you usually been about this behavior? }\end{array}$ \\
\hline
\end{tabular}


Table A1. Cont.

\begin{tabular}{|c|c|c|}
\hline Category & Item Number & Prompt \\
\hline Purging for weight control & Q66 & $\begin{array}{l}\text { Over the past four weeks ( } 28 \text { days), on how many days have you taken laxatives } \\
\text { in larger than recommended amounts (including on product labeling) for any of } \\
\text { the following reasons? (a) To lose weight or avoid gaining weight }\end{array}$ \\
\hline Purging for weight control & Q68 & $\begin{array}{l}\text { Over the past four weeks ( } 28 \text { days), on how many days have you taken diuretics } \\
\text { (water pills) in larger than recommended amounts (including recommendations } \\
\text { on product labeling), for any of the following reasons? (a) To lose weight or avoid } \\
\text { gaining weight }\end{array}$ \\
\hline Purging for weight control & Q70 & $\begin{array}{l}\text { Over the past four weeks ( } 28 \text { days), on how many days have you exercised in a } \\
\text { "driven" or "compulsive" way as a means of controlling your weight, shape, or } \\
\text { amount of fat or to burn off calories? }\end{array}$ \\
\hline \multirow[t]{5}{*}{ Purging for weight control } & Q85 & $\begin{array}{l}\text { If you have ever made yourself vomit in the last four weeks, how distressed or } \\
\text { upset have you usually been about the vomiting? }\end{array}$ \\
\hline & Q20 & $\begin{array}{l}\text { Over the past four weeks ( } 28 \text { days), have there been any days when you felt that } \\
\text { you have eaten too much (given your current circumstances), } \\
\text { even if others might not agree? Please indicate the number of days it occurred } \\
\text { and average number of times per day. If this did not occur, enter } 0 \text { for both fields. } \\
\text { Please enter a number only, with no spaces or text. DAYS }\end{array}$ \\
\hline & Q22 & $\begin{array}{l}\text { Over the past } 28 \text { days, have there been days when you have eaten what } \\
\text { other people would regard as an unusually large amount of food (given your } \\
\text { current circumstances)? Please indicate the number of days it occurred and } \\
\text { average number of times per day, on days when it occurred. If this did not occur, } \\
\text { enter } 0 \text { for both fields. Please enter a number only, with no spaces or text. DAYS }\end{array}$ \\
\hline & Q26 & $\begin{array}{l}\text { Of the times that you picked, nibbled, or grazed in the past } 4 \text { weeks ( } 28 \text { days), how } \\
\text { often was it for any of the following reasons? To lose weight or avoid } \\
\text { gaining weight }\end{array}$ \\
\hline & Q28 & $\begin{array}{l}\text { Please indicate any additional reasons for having picked, nibbled, or grazed in the } \\
\text { past } 4 \text { weeks ( } 28 \text { days): Sadness, loneliness, anxiety, stress, body image } \\
\text { dissatisfaction, or boredom }\end{array}$ \\
\hline
\end{tabular}
Over the past four weeks (28 days), did you have a feeling of loss of control when you picked, nibbled or grazed on food between meals and snacks? Please indicate

Q29 the number of days this occurred and average number of times per day, on days when it occurred. If this did not occur, enter 0 for both fields. Please enter a number only, with no spaces or text. DAYS

Q31 During times that you felt a loss of control over your eating, how often have you experienced any of the following? (a) Eat much more quickly than usual

Q32 During times that you felt a loss of control over your eating, how often have you experienced any of the following? (b) Eat until you feel uncomfortably full

During times that you felt a loss of control over your eating, how often have you

Q33 experienced any of the following? (c) Eat large amounts when you do not feel physically hungry

During times that you felt a loss of control over your eating, how often have you experienced any of the following? (d) Eat alone because you feel embarrassed about how much you are eating

During times that you felt a loss of control over your eating, how often have you experienced any of the following? (e) Feel disgusted with yourself, depressed, or very guilty

Q36 During times that you felt a loss of control over your eating, how often have you experienced any of the following? f. Felt upset or distressed by your eating 
Table A1. Cont.

\begin{tabular}{|c|c|c|}
\hline Category & Item Number & Prompt \\
\hline & Q07 & $\begin{array}{l}\text { Over the past four weeks ( } 28 \text { days), on how many days have you tried to exclude } \\
\text { from your diet any foods that you like, regardless of whether or not you were } \\
\text { successful, for any of the following reasons? (c) To adhere to recommendations } \\
\text { made by a dietitian or other health care professional }\end{array}$ \\
\hline
\end{tabular}

Q10 definite rules regarding your eating (for example, a calorie limit), regardless of whether or not you were successful, for any of the following reasons? (c) To adhere to recommendations made by a dietitian or other health care professional

Over the past four weeks (28 days), have there been any days when you felt that you have eaten too much (given your current circumstances),

Q21 even if others might not agree? Please indicate the number of days it occurred and average number of times per day. If this did not occur, enter 0 for both fields. Please enter a number only, with no spaces or text. Times per day

Over the past 28 days, have there been days when you have eaten what other people would regard as an unusually large amount of food (given your current circumstances)? Please indicate the number of days it occurred and

Q23 average number of times per day, on days when it occurred. If this did not occur, enter 0 for both fields. Please enter a number only, with no spaces or text. Times per day

Over the past four weeks (28 days), have you picked, nibbled or grazed on food

Q24 between meals and snacks? Please indicate the number of days it occurred and average number of times per day, on days when it occurred. If this did not occur, enter 0 for both fields. Please enter a number only, with no spaces or text. DAYS

Over the past four weeks (28 days), have you picked, nibbled or grazed on food between meals and snacks? Please indicate the number of days it occurred and

Q25 average number of times per day, on days when it occurred. If this did not occur, enter 0 for both fields. Please enter a number only, with no spaces or text. Times per day

Q27 Of the times that you picked, nibbled, or grazed in the past 4 weeks (28 days), how often was it for any of the following reasons? (b) To avoid physical discomfort

Over the past four weeks (28 days), did you have a feeling of loss of control when you picked, nibbled or grazed on food between meals and snacks? Please indicate

Q30 the number of days this occurred and average number of times per day, on days when it occurred. If this did not occur, enter 0 for both fields. Please enter a number only, with no spaces or text. Times per day

Of the times when you picked, nibbled, or grazed on food AND had a feeling of loss of control, how often did you eat any of the following foods? (a) Ice cream,

Jell-O, smoothies, and/or other soft foods or beverages

Q38 Of the times when you picked, nibbled, or grazed on food AND had a feeling of loss of control, how often did you eat any of the following foods? (b) Crackers,
cookies, donuts, and/or other baked snacks

O39 the times when you picked, nibbled, or grazed on food AND had a feeling
loss of control, how often did you eat any of the following foods? (c) Meat and/or cheeses

Over the past four weeks (28 days), what time of the day were you most likely to

Q40 have experienced loss of control while nibbling or grazing on food between meals and snacks? Select "None of the time" if you did not experience loss of control. (a) Morning

Over the past four weeks (28 days), what time of the day were you most likely to

Q41 have experienced loss of control while nibbling or grazing on food between meals and snacks? Select "None of the time" if you did not experience loss of control. (b) Around noon 
Table A1. Cont.

\begin{tabular}{|c|c|c|}
\hline Category & Item Number & Prompt \\
\hline & Q42 & $\begin{array}{l}\text { Over the past four weeks ( } 28 \text { days), what time of the day were you most likely to } \\
\text { have experienced loss of control while nibbling or grazing on food between meals } \\
\text { and snacks? Select "None of the time" if you did not experience loss of control. } \\
\text { (c) Afternoon }\end{array}$ \\
\hline
\end{tabular}

Over the past four weeks (28 days), what time of the day were you most likely to

Q43 have experienced loss of control while nibbling or grazing on food between meals and snacks? Select "None of the time" if you did not experience loss of control.

(d) Evening

Over the past four weeks (28 days), what time of the day were you most likely to

Q44 have experienced loss of control while nibbling or grazing on food between meals and snacks? Select "None of the time" if you did not experience loss of control. (e) During the night

Over the past four weeks (28 days), what time of the day were you most likely to

Q45 have experienced loss of control while nibbling or grazing on food between meals and snacks? Select "None of the time" if you did not experience loss of control.

(f) After having slept

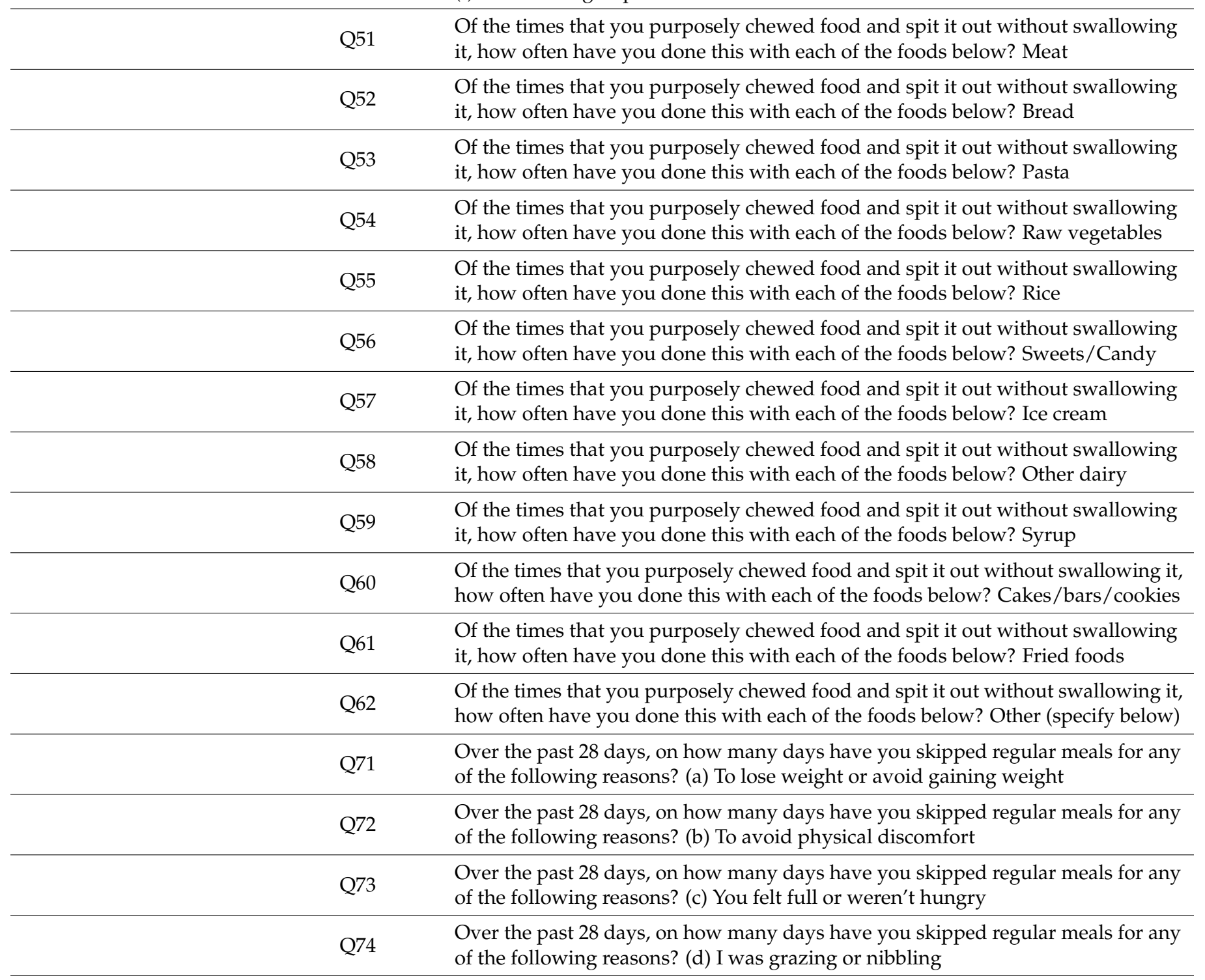


Table A1. Cont.

\begin{tabular}{|c|c|c|}
\hline Category & Item Number & Prompt \\
\hline & Q86 & $\begin{array}{l}\text { Over the past four weeks ( } 28 \text { days), on average, how long have your episodes of } \\
\text { loss of control while nibbling or grazing been (in minutes)? For example, enter } 25 \\
\text { for } 25 \mathrm{~min} \text {, or } 60 \text { for an hour. Please enter a number only, with no spaces or text. }\end{array}$ \\
\hline & Q87 & $\begin{array}{l}\text { What has been the longest duration of an episode of losing control while picking, } \\
\text { nibbling, or grazing (in minutes)? Please enter a number only, with no spaces } \\
\text { or text. }\end{array}$ \\
\hline & Q88 & $\begin{array}{l}\text { What has been the shortest duration of an episode of losing control while picking, } \\
\text { nibbling, or grazing (in minutes)? Please enter a number only, with no spaces } \\
\text { or text. }\end{array}$ \\
\hline & Q89 & $\begin{array}{l}\text { What was your weight in pounds prior to surgery? Please enter a number only, } \\
\text { with no spaces or text. }\end{array}$ \\
\hline & Q90 & $\begin{array}{l}\text { What is your current weight in pounds? Please enter a number only, with no } \\
\text { spaces or text. }\end{array}$ \\
\hline & Q91 & What is your current height? Please enter a number only, with no spaces or text. \\
\hline
\end{tabular}

${ }^{1}$ Questions without a prescribed category may be of clinical use but are not currently used in any distinct scoring or symptom category.

\section{References}

1. Opolski, M.; Chur-Hansen, A.; Wittert, G. The eating-related behaviours, disorders and expectations of candidates for bariatric surgery. Clin. Obes. 2015, 5, 165-197. [CrossRef] [PubMed]

2. de Zwaan, M.; Mitchell, J.E.; Swan-Kremeier, L.; McGregor, T.; Howell, M.L.; Roerig, J.L.; Crosby, R.D. A comparison of different methods of assessing the features of eating disorders in post-gastric bypass patients: A pilot study. Eur. Eat. Disord. Rev. 2004, 12, 380-386. [CrossRef]

3. Busetto, L.; Segato, G.; De Luca, M.; De Marchi, F.; Foletto, M.; Vianello, M.; Valeri, M.; Favretti, F.; Enzi, G. Weight loss and postoperative complications in morbidly obese patients with binge eating disorder treated by laparoscopic adjustable gastric banding. Obes. Surg. 2005, 15, 195-201. [CrossRef] [PubMed]

4. Colles, S.L.; Dixon, J.B.; O'Brien, P.E. Grazing and loss of control related to eating: Two high-risk factors following bariatric surgery. Obesity 2008, 16, 615-622. [CrossRef]

5. Conceição, E.M.; Mitchell, J.E.; Engel, S.G.; Machado, P.P.P.; Lancaster, K.; Wonderlich, S.A. What is "grazing"? Reviewing its definition, frequency, clinical characteristics, and impact on bariatric surgery outcomes, and proposing a standardized definition. Surg. Obes. Relat. Dis. 2014, 10, 973-982. [CrossRef]

6. Cooper, Z.; Fairburn, C. The eating disorder examination: A semi-structured interview for the assessment of the specific psychopathology of eating disorders. Int. J. Eat. Disord. 1987, 6, 1-8. [CrossRef]

7. de Zwaan, M.; Hilbert, A.; Swan-Kremeier, L.; Simonich, H.; Lancaster, K.; Howell, L.M.; Monson, T.; Crosby, R.D.; Mitchell, J.E. Comprehensive interview assessment of eating behavior 18-35 months after gastric bypass surgery for morbid obesity. Surg. Obes. Relat. Dis. 2010, 6, 79-85. [CrossRef]

8. Fairburn, C.G.; Beglin, S.J. Assessment of eating disorders: Interview or self-report questionnaire? Int. J. Eat. Disord. 1994, 16, 363-370. [CrossRef]

9. Goldfein, J.A.; Devlin, M.J.; Kamenetz, C. Eating disorder examination-questionnaire with and without instruction to assess binge eating in patients with binge eating disorder. Int. J. Eat. Disord. 2005, 37, 107-111. [CrossRef]

10. Grilo, C.M.; Masheb, R.M.; Wilson, G.T. A comparison of different methods for assessing the features of eating disorders in patients with binge eating disorder. J. Consult. Clin. Psychol. 2001, 69, 317-322. [CrossRef]

11. Binford, R.B.; Le Grange, D.; Jellar, C.C. Eating Disorders Examination versus Eating Disorders Examination- Questionnaire in adolescents with full and partial-syndrome bulimia nervosa and anorexia nervosa. Int. J. Eat. Disord. 2005, 37, 44-49. [CrossRef]

12. Kalarchian, M.A.; Terence Wilson, G.; Brolin, R.E.; Bradley, L. Assessment of eating disorders in bariatric surgery candidates: Self-report questionnaire versus interview. Int. J. Eat. Disord. 2000, 28, 465-469. [CrossRef]

13. Wilfley, D.E.; Schwartz, M.B.; Spurrell, E.B.; Fairburn, C.G. Assessing the specific psychopathology of binge eating disorder patients: Interview or self-report? Behav. Res. Ther. 1997, 35, 1151-1159. [CrossRef]

14. Mond, J.M.; Hay, P.J.; Rodgers, B.; Owen, C.; Beumont, P.J.V. Validity of the Eating Disorder Examination Questionnaire (EDE-Q) in screening for eating disorders in community samples. Behav. Res. Ther. 2004, 42, 551-567. [CrossRef]

15. Wolk, S.L.; Loeb, K.L.; Walsh, B.T. Assessment of patients with anorexia nervosa: Interview versus self-report. Int. J. Eat. Disord. 2005, 37, 92-99. [CrossRef] [PubMed]

16. Sysko, R.; Walsh, B.T.; Fairburn, C.G. Eating disorder examination-questionnaire as a measure of change in patients with bulimia nervosa. Int. J. Eat. Disord. 2005, 37, 100-106. [CrossRef] 
17. Carter, J.C.; Aime, A.A.; Mills, J.S. Assessment of bulimia nervosa: A comparison of interview and self-report questionnaire methods. Int. J. Eat. Disord. 2000, 30, 187-192. [CrossRef]

18. Barnes, R.D.; Masheb, R.M.; White, M.A.; Grilo, C.M. Comparison of Methods for Identifying and Assessing Obese Patients with Binge Eating Disorder in Primary Care Settings. Int. J. Eat. Disord. 2011, 157-164. [CrossRef] [PubMed]

19. Williams-Kerver, G.A.; Steffen, K.J.; Mitchell, J.E. Eating Pathology After Bariatric Surgery: An Updated Review of the Recent Literature. Curr. Psychiatry Rep. 2019, 21, 86. [CrossRef] [PubMed]

20. Halliday, T.A.; Sundqvist, J.; Hultin, M.; Walldén, J. Post-operative nausea and vomiting in bariatric surgery patients: An observational study. Acta Anaesthesiol. Scand. 2017, 61, 471-479. [CrossRef]

21. Kalarchian, M.A.; King, W.C.; Devlin, M.J.; White, G.E.; Marcus, M.D.; Garcia, L.; Yanovski, S.Z.; Mitchell, J.E. Surgery-related gastrointestinal symptoms in a prospective study of bariatric surgery patients: 3-year follow-up. Surg. Obes. Relat. Dis. 2017, 13, 1562-1571. [CrossRef] [PubMed]

22. Conceição, E.; Orcutt, M.; Mitchell, J.; Engel, S.; Lahaise, K.; Jorgensen, M.; Woodbury, K.; Hass, N.; Garcia, L.; Wonderlich, S. Eating disorders after bariatric surgery: A case series. Int. J. Eat. Disord. 2013, 46, 274-279. [CrossRef] [PubMed] 